\title{
Aspectos citoquímicos e morfológicos de elementos sanguíneos das serpentes dos gêneros Bothrops e Crotalus mantidas em cativeiro no serpentário do Instituto Vital Brasil
}

\author{
[Cytochemical and morphological aspects of blood cells from Bothrops and Crotalus kept in captivity in the \\ serpentarium of the Institute Vital Brazil] \\ L.M. Kindlovits ${ }^{1}$, L.F.C. Temoche ${ }^{1}$, C. Machado $^{2}$, N.R.P. Almosny ${ }^{1 *}$ \\ ${ }^{1}$ Faculdade de Veterinária - Universidade Federal Fluminense - Niterói, RJ \\ ${ }^{2}$ Instituto Vital Brasil - Niterói, RJ
}

\begin{abstract}
RESUMO
A criação de serpentes peçonhentas em cativeiro vem se tornando prática cada vez mais difundida no país. Dessa forma, o conhecimento do manejo e da clínica de serpentes se torna prioritário, a fim de permitir maior sobrevida dos animais. No que concerne a serpentes peçonhentas, dados hematológicos já foram descritos na literatura, no entanto, apesar dos recursos utilizados, os dados analisados ainda são insipientes. Com o objetivo de caracterizar, morfologicamente, as células sanguíneas e de esclarecer diferenças morfológicas e funcionais, foram coletadas amostras de sangue de 50 serpentes pertencentes ao plantel do Instituto Vital Brasil. Foram confeccionados e analisados por microscopia óptica e citoquimicamente os esfregaços sanguíneos corados por métodos de Romanowsky e citoquímicos. Foi possível diferenciar as células, caracterizar e confirmar a existência de eosinófilo em B. atrox e C. durissus. Concluiu-se que a caracterização celular pode fornecer evidências indispensáveis ao entendimento da fisiologia de serpentes.
\end{abstract}

Palavras-chave: citoquímica, eosinófilos, ofídios

\begin{abstract}
Breeding of venomous snakes in captivity is becoming increasingly widespread in the country, so clinical and management knowledge on these animals has become priority to increase survival of animals. Regarding venomous snakes, hematological data have been described in some studies; however, despite the resources used, data analyzed are still unrecognized. Aiming to characterize morphology of blood cells and clarify morphological and functional differences, blood samples were collected from 50 snakes belonging to the Instituto Vital Brazil squad. Blood smears were prepared and analyzed by optical microscopy and cytochemistrically, stained by Romanowsky and cytochemical methods. Cell differentiation was possible as well as characterization and confirmation of eosinophil in $\mathrm{B}$. atrox and C. durissus. In conclusion, cell characterization can provide vital evidence to the understanding of the physiology of snakes.
\end{abstract}

Keywords: cytochemistry, eosinophil, snakes

\section{INTRODUÇÃO}

A produção de soro antiofídico e de subprodutos biológicos tem como base a manutenção em cativeiro das diversas espécies de serpentes, principalmente dos gêneros Bothrops e Crotalus. Para que isso ocorra, além do conhecimento da biologia da espécie, há uma necessidade

Recebido em 1 de julho de 2016

Aceito em 29 de setembro de 2016

*Autor para correspondência (corresponding author)

E-mail: nadiaalmosny@id.uff.br crescente da avaliação do estado de saúde das serpentes para manter os indivíduos saudáveis e identificar precocemente as moléstias que possam reduzir a produção de veneno. Muito já foi estudado sobre hematologia de mamíferos selvagens, de forma a se observar o uso rotineiro desses exames por veterinários especializados nessa classe (Campbell, 2004). Entretanto, apesar de existirem trabalhos referentes à hematologia 
desde décadas passadas, a literatura ainda se mostra escassa de valores fisiológicos regionais e sazonais em animais selvagens, particularmente serpentes peçonhentas da fauna brasileira. Por isso, o estabelecimento desses valores é extremamente importante. Assim, o objetivo do presente estudo foi caracterizar morfológica e citoquimicamente as células sanguíneas de serpentes de diferentes espécies dos gêneros Bothrops e Crotalus.

\section{MATERIAL E MÉTODOS}

O presente estudo foi autorizado pela Comissão de Ética no Uso de Animais do Instituto Vital Brasil, sob o $\mathrm{n}^{\mathrm{o}}$ de protocolo 008/2015.

Foram utilizados, no presente estudo, 10 indivíduos de Bothrops jararaca, 10 de Bothrops jararacussu, oito de Bothrops atrox, quatro de Bothrops pauloensis, cinco de Bothrops neuwiedi, um de Bothrops alcatraz, dois de Bothrops alternatus e 10 indivíduos Crotalus durissus, pertencentes à divisão de Herpetologia do Instituto Vital Brasil, situado na cidade de Niterói, Rio de Janeiro, com o intuito de caracterizar as células sanguíneas sob microscopia óptica em colorações Romanowsky e citoquímicas.

Os animais foram selecionados, independente do sexo e idade, após verificação da sanidade por exame físico. Foram observados grau de desidratação, escore corporal, mucosas aparentes, respiração, aspectos neurológicos, evidências de traumas físicos, presença de ectoparasitos e demais achados relevantes. Os animais foram retirados dos seus recintos, sendo contidos fisicamente utilizando-se um tubo transparente com o auxílio de um gancho herpetológico (McDonald, 1976). Foi realizada punção da veia coccígea ventral utilizando-se seringa de $1 \mathrm{~mL}$ com uma agulha $20 \times 5,5$. As amostras foram acondicionadas em tubos cônicos de plástico tipo Eppendorf ${ }^{\circledR}$ rinsado com heparina sódica 5000UI, conforme proposto por Santos e Cubas (2007).

Realizou-se a diluição do sangue em líquido de Gower, na proporção de 1:100, para a contagem de eritrócitos, plaquetas e leucócitos na câmara de Neubauer improved ${ }^{\circledR}$ conforme proposto por Almosny e Monteiro (2006). Os esfregaços foram confeccionados sem o uso de anticoagulante e, posteriormente, corados utilizando-se os corantes do tipo Romanowsky (Panóptico ${ }^{\circledR}$, Giemsa e Wright). As colorações dos tipos Panóptico ${ }^{\circledR}$ e Wright (Merck $\left.{ }^{\circledR}\right)$ foram realizadas conforme o fabricante.

Foram confeccionados esfregaços sem anticoagulante para realização das colorações citoquímicas: peroxidase (método benzidina) e sudan black $B$ (SBB). Para a coloração de peroxidase, não foi necessária a fixação prévia dos esfregaços sanguíneos, porém, para tal coloração, foi preciso que fossem utilizados esfregaços recentemente confeccionados. Para a coloração sudan black, os esfregaços foram fixados em vapor de formol $20 \%$. Esta metodologia foi efetuada conforme Jain (1986).

\section{RESULTADOS E DISCUSSÃO}

A morfologia das células sanguíneas das espécies de serpentes estudadas no presente estudo apresentou-se uniforme na avaliação em esfregaço sanguíneo, realizada de acordo com o relatado por vários outros autores (Egami e Sasso, 1988; Campbell, 1991; Dotson et al., 1995; Mader, 2006; Alleman et al., 1999; Almosny e Santos, 2000; Silva, et al., 2010; Almosny, 2014).

Os tipos de leucócitos observados estavam em conformidade com a morfologia e a nomenclatura proposta por Hawkey e Dennet (1989); Almosny e Monteiro (2006) e Almosny (2014), que as classificaram em células mononucleadas (linfócitos, monócitos e azurófilos) e granulócitos (heterófilos e basófilos). No estudo atual, foi considerada a presença de azurófilos e monócitos, em separado, seguindo o mesmo critério adotado por outros autores (Troiano et al., 1997; Santos, 2005; Almosny e Monteiro, 2006).

Em colorações do tipo Romanowsky, observaram-se diferenças sutis entre as colorações. A coloração de Giemsa foi a que possibilitou o melhor resultado quando comparada com as demais.

Os eritrócitos maduros eram elípticos, alongados e em colorações de base Romanowsky; seus citoplasmas apresentavam coloração uniforme, variando em tons de vermelho a púrpura. O núcleo possuía uma cromatina condensada 
central, de coloração basofílica, que acompanhava o eixo da célula. Observou-se que $10 \%$ dos eritrócitos estavam parasitados por Hepatozoon sp., dois indivíduos da espécie $B$. jararacussu , um C. durissus , um B. atrox e um B. jararaca (Fig. 1a). Observou-se, ainda, a presença de protozoário não identificado em $8 \%$ das serpentes analisadas, em apenas um indivíduo na espécie $C$. durissus, um na $B$. pauloensis, um na $B$. neuwiedi e um na $B$. jararaca.
Nas avaliações citoquímicas, observou-se que os eritrócitos eram peroxidase negativos (Tab. 1), para todas as espécies (Fig. 1c), conforme também foi observado por Egami e Sasso (1988) e Rodrigues (2000), em estudos com a espécie $B$. jararaca. $\mathrm{Na}$ coloração $\mathrm{SBB}$, a reação foi negativa (Tab. 2), em todas as espécies (Fig. 1b), corroborando os achados de Salakij et al. (2002). Egami e Sasso (1988), entretanto, relataram que eritrócitos de Bothrops eram sudan black positivos.

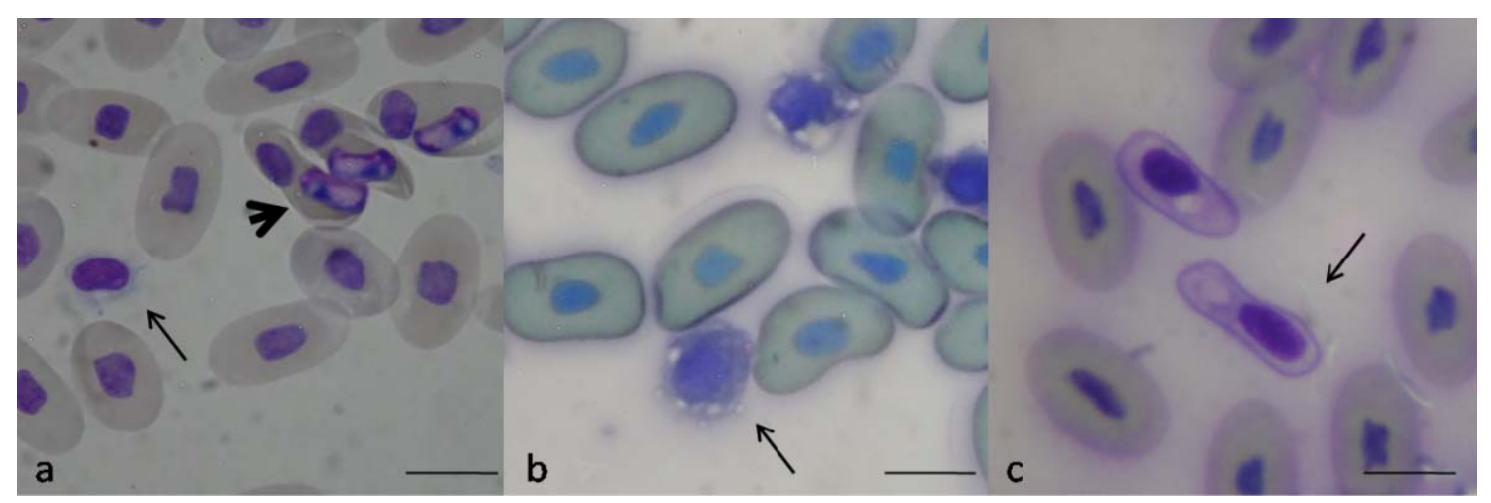

Figura 1 Imagens obtidas por microscopia óptica de diferentes células sanguíneas de serpentes dos gêneros Bothrops e Crotalus; barra $10 \mu \mathrm{m}$. (a) Eritrócitos parasitados por Hepatozoon sp. (cabeça de seta), trombócito (seta) de B. atrox. Coloração Giemsa. (b) Eritrócito e trombócitos (seta) de B. jararaca. Coloração sudan black B (SBB). (c) Eritrócitos e trombócitos (seta) de C. durissus. Coloração peroxidase (POX).

Tabela 1. Resultado da coloração de peroxidase (método benzidina) das células sanguíneas, de amostras de serpentes do Instituto Vital Brasil

\begin{tabular}{l|l|l|l|l|l|l|l|c}
\hline \multicolumn{1}{|c|}{} & Eos & Bas & Azu & Mon & Het & Linf & Eri & Tromb \\
\hline B. pauloensis & Neg. & Neg. & Pos. & Neg. & Neg. & Neg. & Neg. & Neg. \\
\hline B. alternatus & Neg. & Neg. & Pos. & Neg. & Neg. & Neg. & Neg. & Neg. \\
\hline B. neuwiedi & Neg. & Neg. & Pos. & Neg. & Neg. & Neg. & Neg. & Neg. \\
\hline B. atrox & Neg. & Neg. & Pos. & Neg. & Neg. & Neg. & Neg. & Neg. \\
\hline B. alcatraz & Neg. & Neg. & Pos. & Neg. & Neg. & Neg. & Neg. & Neg. \\
\hline B. jararaca & Neg. & Neg. & Pos. & Neg. & Neg. & Neg. & Neg. & Neg. \\
\hline B. jararacussu & Neg. & Neg. & Pos. & Neg. & Neg. & Neg. & Neg. & Neg. \\
\hline C. durissus & Neg. & Neg. & Pos. & Neg. & Neg. & Neg. & Neg. & Neg.
\end{tabular}

Neg. = negativo. Pos. $=$ positivo (independente da intensidade da reação). Eos $=$ eosinófilo, Bas $=$ basófilo, Azu $=$ azurófilo, Mon $=$ monócito, Het $=$ heterófilo, $\operatorname{Linf}=$ linfócito, Eri $=$ eritrócito, Tromb $=$ trombócito. 
Tabela 2. Resultado da coloração de sudan black B das células sanguíneas, de amostras de serpentes do Instituto Vital Brasil

\begin{tabular}{|c|c|c|c|c|c|c|c|c|}
\hline \multicolumn{9}{|c|}{ Sudan black B } \\
\hline & Eos & Bas & $\mathrm{Azu}$ & Mon & Het & Linf & Eri & Tromb \\
\hline B. pauloensis & Neg. & Neg. & Pos. & Neg. & Pos. & Neg. & Neg. & Neg. \\
\hline B. alternatus & Neg. & Neg. & Pos. & Neg. & Pos./ Neg. & Neg. & Neg. & Neg. \\
\hline B. neuwiedi & Neg. & Neg. & Neg. & Neg. & Pos. /Neg & Neg. & Neg. & Neg. \\
\hline B. atrox & Neg. & Neg. & Pos. & Neg. & Pos. & Neg. & Neg. & Neg. \\
\hline B. alcatraz & Neg. & Neg. & Pos. & Neg. & Pos. & Neg. & Neg. & Neg. \\
\hline B. jararaca & Neg. & Neg. & Pos. & Neg. & Pos. & Neg. & Neg. & Neg. \\
\hline B. jararacussu & Neg. & Neg. & Pos. & Neg. & Pos./ Neg. & Neg. & Neg. & Neg. \\
\hline C. durissus & Neg. & Neg. & Pos./ Neg. & Neg. & Pos./ Neg. & Neg. & Neg. & Neg. \\
\hline
\end{tabular}

Neg. = negativo. Pos. $=$ positivo (independente da intensidade da reação). Pos./Neg. $=$ positivo e negativo na mesma coloração. * Positivo para células maduras e negativo para células jovens. Eos = eosinófilo, Bas $=$ basófilo, $\mathrm{Azu}=$ azurófilo, $\mathrm{Mon}=$ monócito, Het $=$ heterófilo, Linf $=$ linfócito, Eri $=$ eritrócito, Tromb $=$ trombócito.

Os monócitos observados neste estudo eram células de tamanho grande quando comparados aos linfócitos. Possuíam um formato arredondado e citoplasma abundante com tonalidade azulada, quando visualizados em coloração do tipo Romanowsky (Fig. 2a). O núcleo, de coloração basofílica, era irregular, variando de redondo a riniforme, e com uma cromatina mais frouxa (Rodrigues, 2000; Kindlovits, 2012). Foram observados vacúolos citoplasmáticos, principalmente quando essas células estavam ativadas.

Todas as serpentes do presente estudo apresentaram monócitos com reação negativa tanto na coloração SBB (Tab. 1 e 2) quanto na peroxidase (Fig. 2e).

Embora haja consenso de que essas células sejam monócitos, no presente estudo optou-se por descrever os azurófilos em separado, conforme Silva et al. (2010); Kindlovits (2012) e Almosny (2014), tendo em vista as diferenças citoquímicas entre ambas. Essas células eram mononucleadas, de formato arredondado e variavam em tamanho, de pequeno a grande. $\mathrm{O}$ citoplasma era basofílico e abundante, em coloração do tipo Romanowsky, e apresentava uma fina e delicada granulação rosa a lilás intenso, como foi observado também por Silva et al. (2010) e Kindlovits (2012) (Fig. 2a). Vacúolos de diferentes tamanhos e quantidade variada foram observados com frequência. $\mathrm{O}$ núcleo era relativamente grande, com localização central ou excêntrica, com a cromatina densa. Tais características também foram observadas por Saint Girons (1970);
Montali (1988); Dotson et al. (1995); Rodrigues (2000) e Kindlovits (2012).

$\mathrm{O}$ SBB revelou reação positiva e negativa nos azurófilos (Tab. 2). A intensidade da reação, ou seja, o número de grânulos positivos e sua disposição no citoplasma também variavam individualmente (Fig. 2b). Nas espécies B. atrox, B. jararaca, B. jararacussu e B. pauloensis, os azurófilos estavam discretamente positivos, assim como foi observado por Egami e Sasso (1988) e Rodrigues (2000), em estudos com $B$. jararaca. Os azurófilos das espécies $B$. alternatus e $C$. durissus foram SBB positivos e em B. neuwiedi a reação foi negativa, como foi observado por Rodrigues (2000) em outras espécies do gênero Bothrops. No método de peroxidase, os azurófilos apresentaram reação positiva (Tab. 1) com coloração dourada, variando para tons de marrom-enegrecido. Entretanto, alguns grânulos que apresentavam essa característica apareciam no citoplasma como uma "pequena mancha" (Fig. 2c). A reação foi positiva em todas as espécies, porém $C$. durissus e B. alternatus apresentaram também azurófilos negativos, corroborando os achados de Rodrigues (2000), que relatou que podem ser encontradas, no mesmo indivíduo, células positivas e negativas para a mesma coloração. Egami e Sasso (1988), em estudo com B. jararaca, descreveram o azurófilo como a única célula positiva para essa coloração.

Apesar de haver consenso de que os azurófilos sejam monócitos, estes primeiros foram positivos na POX, da mesma forma que são os neutrófilos 
dos mamíferos, enquanto os monócitos foram peroxidase negativos. Acredita-se, portanto, que monócitos e azurófilos sejam células com funções distintas.

Os linfócitos observados eram pequenos, sendo menores que os eritrócitos (cerca de 1/3 do seu tamanho), e tinham um formato arredondado, corroborando os achados de Rodrigues (2000). O citoplasma era pequeno de coloração cinzaazulada, enquanto o núcleo era redondo e ocupava grande parte da célula. A cromatina nuclear era bem condensada e apresentava coloração arroxeada, quando corada com colorações do tipo Romanowsky (Fig. 2g). Foram observados linfócitos reativos, que apresentavam um citoplasma abundante e intensamente basofílico, como descrito por Mader (2006), e linfócitos contendo granulações inespecíficas. Esses grânulos se coravam em tons de roxo bem intenso e estavam dispostos no citoplasma em quantidade que variava de poucos até numerosos, chegando a encobrir praticamente todo o citoplasma (Fig. 2f); achados similares foram descritos por Kindlovits (2012). Os linfócitos não apresentaram reação positiva para peroxidase (Tab. 1) nem para SBB (Tab. 2), em todas as espécies estudadas (Fig. 2h, i), conforme também relataram Caxton-Martins e Nganwuch, (1978); Rodrigues (2000); Salakij et al. (2002) e Chansue et al. (2011).

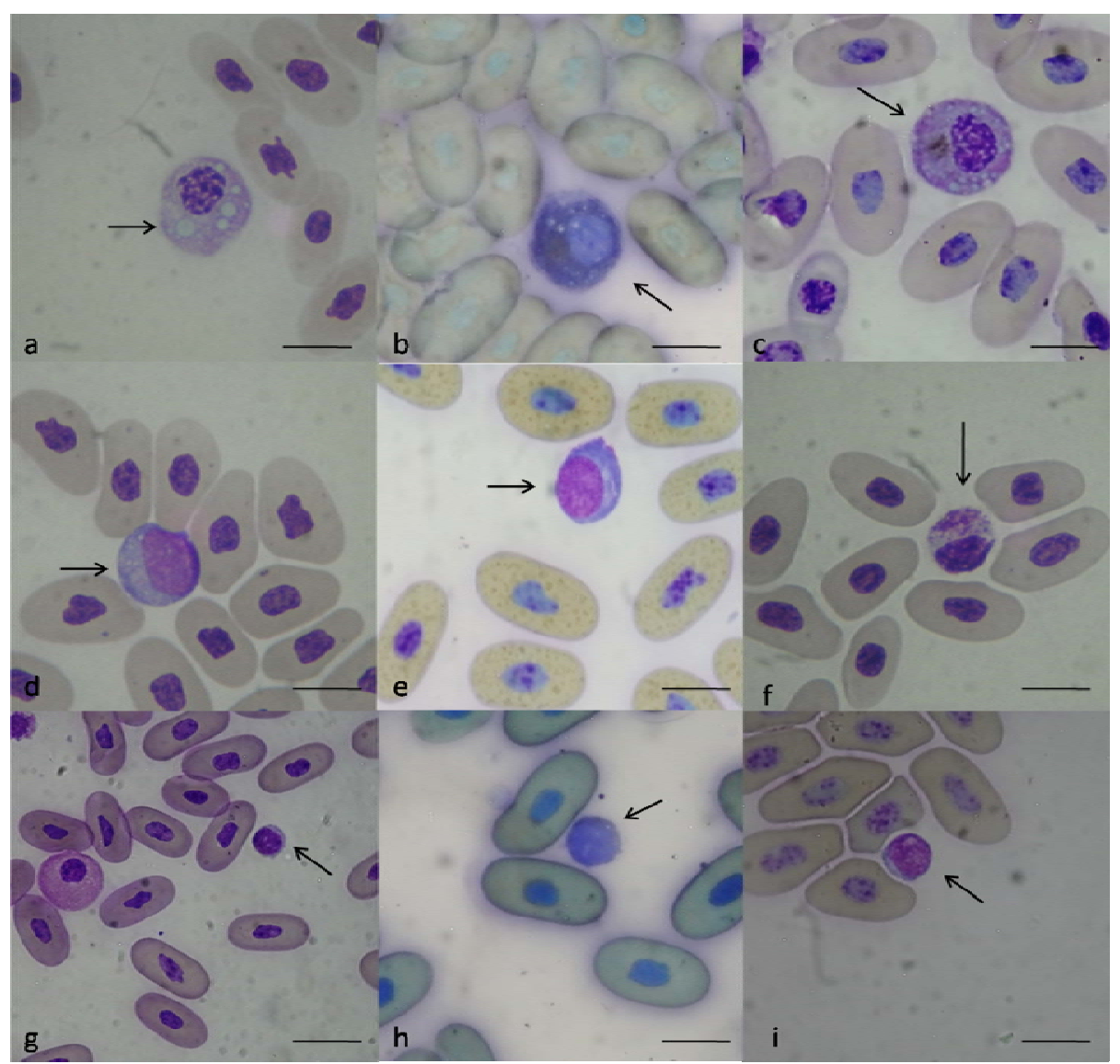

Figura 2. Imagem obtida por microscopia óptica de diferentes células sanguíneas de serpentes dos gêneros Bothrops e Crotalus; barra $10 \mu \mathrm{m}$. (a) Azurófilo apresentando vacuolizações (seta) em B. jararaca. Coloração Giemsa. (b) Azurófilo em B. atrox (seta). Coloração sudan black B (SBB). (c) Azurófilo em B.atrox (seta) apresentando granulação marrom-enegrecida no citoplasma. Coloração peroxidase (POX). (d) Monócito em B. jararaca (seta). Coloração Giemsa. Monócito em B. atrox. Coloração POX. (f) Linfócitos apresentando granulação basofílica no citoplasma (seta) em B. atrox. Coloração Giemsa. (g) Linfócito (seta) em B. alternatus. Coloração Giemsa. (h) Linfócito em B. jararaca (seta). Coloração SBB. (i) Linfócito (seta) em B. atrox. Coloração POX. 
Em colorações Romanowsky, os basófilos apresentavam grande número de grânulos de coloração intensamente basofílica no citoplasma, o que dificultava a visualização do núcleo (Fig. 3a). O aspecto "amora" observado foi descrito por Rodrigues (2000) e Silva et al. (2009). No método de peroxidase (Tab. 1), os basófilos apresentaram reação negativa (Fig. 3c) em todas as espécies estudadas. No SBB, o basófilo foi negativo (Fig. 3b) para todas as espécies avaliadas neste estudo (Tab. 2), assim como foi descrito por Egami e Sasso (1988) em $B$. jararaca.

Foram observados eosinófilos em dois indivíduos de $B$. atrox e em um de $B$. jararacussu. Essa célula possuía um tamanho grande, núcleo pequeno e excêntrico, cromatina condensada e de cor roxa bem intensa, em coloração do tipo Romanowsky (Fig. 3d). O citoplasma era todo coberto por grânulos redondos, grandes e de coloração basofílica, em que a tonalidade variava em tons de azul. Em $B$. jararacussu, os grânulos eram mais discretos que na espécie B. atrox. Alleman et al. (1999), em estudos com Crotalus adamanteus, não observaram eosinófilos, assim como também não foram encontrados em serpente de rabo amarela e B. jararaca por Dotson et al. (1995). Egami e Sasso (1988); Campbell (1996) e Troiano et al. (1997) entretanto, descreveram eosinófilos em algumas subespécies do gênero Crotalus da América do Sul e na serpente índigo. Os eosinófilos apresentaram reação negativa em coloração de POX (Fig. 3f) (Tab. 1), ao contrário do que foi observado por Mader (1996) em eosinófilos de animais da ordem Squamata, e do que foi relatado no estudo com Alligator massissippiensis, realizado por Mateo et al. (1984), em que os eosinófilos eram POX positivos. Na coloração SBB (Tab. 2), essa célula, apresentou o núcleo de coloração basofílica mais clara e seus grânulos variando em tons de lilás a azul (Fig. 3e).

Foram observados heterófilos íntegros e degranulados, assim como foi relatado por Grego et al. (2006), e ambos apresentavam características morfológicas semelhantes, exceto a degranulação. Apresentaram-se como células grandes, com núcleo pequeno e excêntrico, de coloração roxa a enegrecida, em coloração do tipo Romanowsky, com um contorno discretamente irregular, contendo uma cromatina densa, assim como foi descrito por Almosny e Santos (2000); Campbell e Lamar (2004); Silva et al. (2010) e Kindlovits (2012). O heterófilo íntegro apresentava em seu citoplasma grânulos grandes e pleomórficos, que variavam entre redondos a elípticos e tinham coloração eosinofílica bem intensa, mas de tonalidade variada. A degranulação (Fig. 3g) era observada em animais que apresentavam algum tipo de processo inflamatório, conforme também observaram Kindlovits (2012) e Almosny (2014). Em alguns indivíduos, observaram-se heterófilos tóxicos, que apresentavam granulações basofílicas a enegrecidas (Fig. 3j) e de formato variado, e heterófilos apresentando vacúolos, os quais, segundo Rovira (2010), correspondiam à atividade fagocitária da célula.

$\mathrm{Na}$ reação de peroxidase, ambas as formas de heterófilos (Fig. 3f, i) foram negativas (Tab. 1), corroborando os achados de Egami e Sasso (1988), que estudaram as características do sangue de B. jararaca. Montalli (1998) relatou que existe uma reação moderada para a peroxidase nos animais da ordem Squamata. $\mathrm{Na}$ reação de SSB, observou-se que, quando positivos, os grânulos dos heterófilos apresentavam uma coloração castanhoamarronzada que variava de intensidade (Tab. 2). Foram encontrados em $B$. alternatus heterófilos fraca e fortemente positivos. Em B. atrox, os heterófilos íntegros foram negativos, entretanto os heterófilos degranulados apresentaram uma reação fracamente positiva. Em B. neuwiedi, foram visualizados heterófilos moderada $\mathrm{e}$ intensamente positivos. Em B. jararaca, ambas as formas tiveram uma reação fracamente positiva. Em B. jararacussu, B. pauloensis e C. durissus, foram encontrados heterófilos com reação positiva e heterófilos negativos (Fig. 3h, l)

Foram observados trombócitos no sangue circulante de todas as espécies, por meio da coloração do tipo Romanowsky. $\mathrm{Na}$ forma inativa, essas células apresentavam-se alongadas, menores que os eritrócitos, parecendo ter uma "membrana" delgada, de coloração levemente basofílica, que delimitava um citoplasma hialino, um núcleo centralizado bem condensado de formato oval ou redondo e de coloração escura (Almosny e Santos, 2000; Rovira, 2010 e Silva et al., 2010). Na sua forma ativa, essas células, muitas vezes, eram encontradas agrupadas, 
pareciam estar "rompidas" ou "retorcidas" com uma proporção núcleo:citoplasma bem menor. A membrana citoplasmática não apresentava uma forma definida, e suas margens eram irregulares, podendo constituir-se de prolongamentos em forma de espículos. Os trombócitos apresentaram reação negativa para a peroxidase (Tab. 1). Em coloração SBB, a reação foi igualmente negativa (Tab. 2), conforme também relataram CaxtonMartins e Nganwuch, (1978); Alleman et al. (1992) e Salakij et al. (2002).

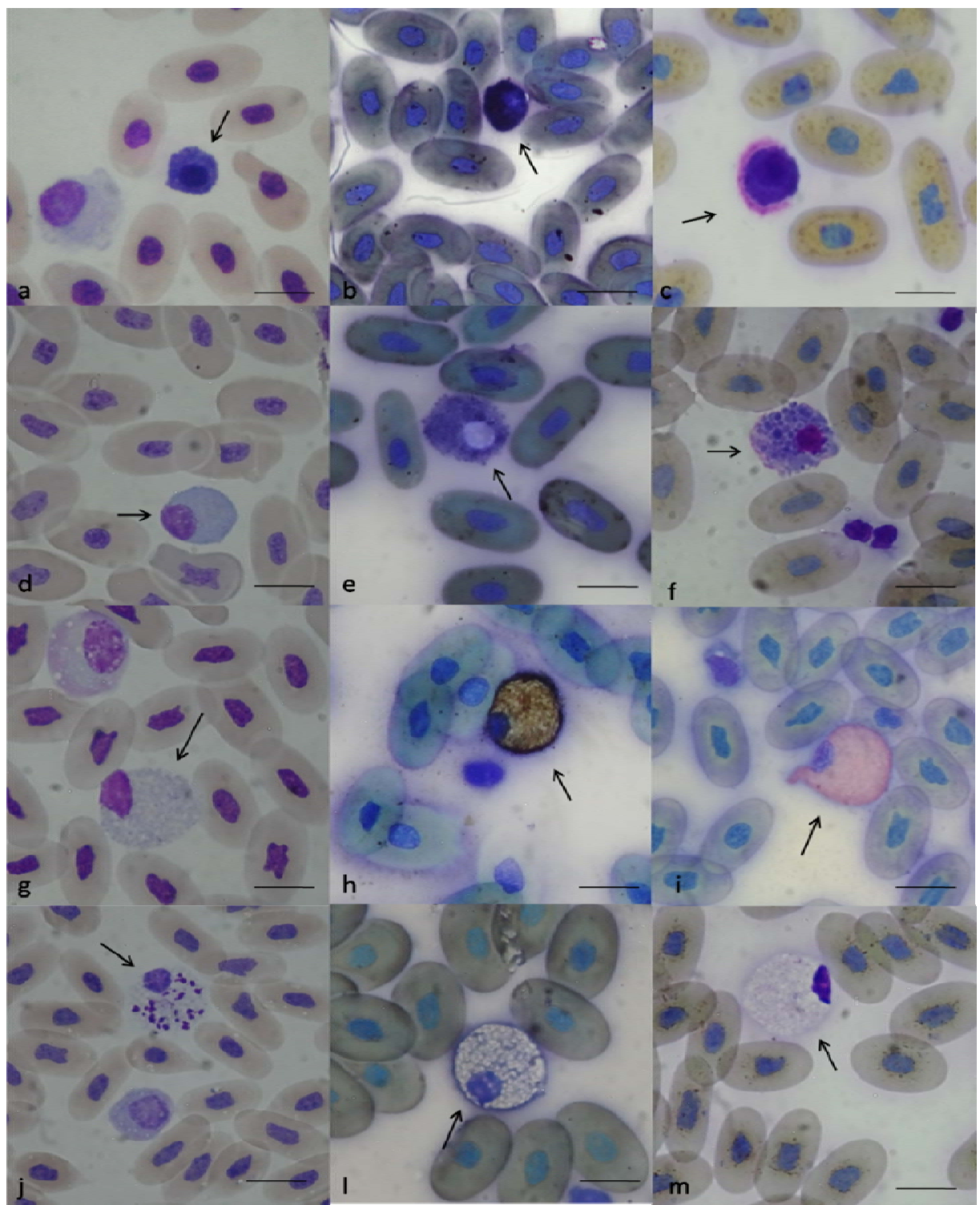

Figura 3. Imagem obtida por microscopia óptica dos granulócitos presentes no sangue de serpentes dos gêneros Bothrops e Crotalus; barra $10 \mu \mathrm{m}$. (a) Basófilo com seus grânulos evidenciados (seta) em $B$. jararaca. Coloração Giemsa. (b) Basófilo (seta) em B. atrox. Coloração sudan black B (SBB). (c) Basófilo (seta) em B. atrox. Coloração peroxidase (POX). (d) Eosinófilo (seta) em B. jararacussu. Coloração Giemsa. (e) Eosinófilo em B.atrox (seta). Coloração SBB. (f) Eosinófilo em B. atrox (seta). Coloração POX. (g) Heterófilo em B. jararacussu (seta). Coloração Giemsa. (h) Heterófilo em C.durissus (seta). Coloração SBB. (i) Heterófilo íntegro de B. pauloensis (seta). Coloração POX. (j) Heterófilo tóxico em B. atrox (seta). Coloração Giemsa. (1) Heterófilo degranulado em C. durissus ( seta). Coloração SBB. (m) Heterófilo degranulado em B. jararacussu (seta). Coloração POX. 


\section{CONCLUSÕES}

As colorações dos esfregaços sanguíneos das serpentes Bothrops jararaca, Bothrops jararacussu, Bothrops atrox, Bothrops pauloensis, Bothrops neuwiedi, Bothrops alcatraz, Bothrops alternatus e Crotalus durissus pelos métodos de Romanowsky e citoquímicos permitem caracterizar morfologicamente as células. As colorações hematológicas tipo Romanowsky favorecem a avaliação morfológica, porém as colorações pelo método de Giemsa são as que diferenciam melhor as células sanguíneas em serpentes. A avaliação citoquímica permite evidenciar as características químicas das células sanguíneas, por meio de reações químicas, revelando substâncias intracelulares com cores específicas, perceptíveis à microscopia óptica, e isto é importante na compreensão da bioquímica da célula sanguínea. Existem eosinófilos, em indivíduos das espécies B. atrox e C. durissus, que podem ser detectados tanto pela coloração Giemsa quanto pelas colorações citoquímicas POX e SBB. Na reação de SBB, é possível observar nos heterófilos que a reação e a sua intensidade, pode variar de acordo com a degranulação da célula. As células sanguíneas caracterizadas como azurófilos são positivas na POX, da mesma forma que são os neutrófilos dos mamíferos, logo considera-se que a função de neutrófilos e azurófilos seja semelhante. Os monócitos são peroxidase negativos. Acredita-se que, mesmo que muitos autores classifiquem o azurófilo como um tipo de monócito, essas células possuem funções distintas. Novos trabalhos, entretanto, devem ser realizados visando à caracterização dessa célula durante reação inflamatória.

\section{REFERÊNCIAS}

ALLEMAN, A.R.; JACOBSON, E.R.; RASKIN, R.E. Morpholologic and cytochemical characteristics of blood cells from the desert tortoise (Gopheus agassizii). Am. J. Vet. Res., v.53, p.1645-1651, 1992.

ALLEMAN, A.R.; JACOBSON, E.R.; RASKIN, R.E. Morpholologic and cytochemical staining, and ultraestructural characteristics of blood cells from eastern diamond black rattlesnakes (Crotalus adamanteus). Am. J. Vet. Res., v.60, p.507-514, 1999
ALMOSNY, N.R.P. Patologia clínica em vertebrados ectotérmicos In: CUBAS, Z.S.; SILVA, J.C.S.; CATÃO-DIAS, J.L. Tratado de animais selvagens 2.ed. Medicina veterinária. São Paulo: Roca, 2014. p.1597-1623.

ALMOSNY, N.R.P.; MONTEIRO, A.M. Patologia clínica. In: CUBAS, Z.S.; SILVA, J.C.S.; CATÃO-DIAS, J.L. Tratado de animais selvagens: medicina veterinária. São Paulo: Roca, 2006. p.939-966.

ALMOSNY, N.R.P.; SANTOS, L.C. Laboratory in wild animals. In: FOWLER, M. Biology, medicine and surgery of South American wild animals. Iowa: Iowa State Universit, 2000. p.300-320.

ALMOSNY, N.R.P.; SANTOS, L.C. Laboratory support in wild animal medicine. In: FOWLER, M. Biology, medicine and surgery of South American wild animals. Iowa: Iowa StateUniversit, 2001. p.300-505.

CAMPBELL, T.W. Hematologia de répteis. In: Hematologia e bioquímica clínica veterinária. 2.ed. São Paulo: ROCA, 1991. cap.20. p.239255.

CAMPBELL, J.A.; LAMAR, W.W. The venomous reptiles of the western hemisphere. Ithaca: Cornell University Press. 2004. 976p.

CAXTON-MARTINS, A.E.; NGANWUCHU, A.M. A cytochemical study of the blood of the rainbow lizard (Agama agama). J. Anat., v.125, p.477-480,1978.

CHANSUE, N.; SAILASUTA, A.; TANGTRONGPIROS, J. et al. Hematology and clinical chemistry of adult yellow-headed temple turtles (Hieremy sannandalli) in Thailand. Vet. Clin. Pathol., v.40, p.174-184. 2011.

DOTSON, T.K.; RAMSAY, E.R.; DENISE, I.B. A color atlas of blood cells of the yellow rat snake. Small Anim. Comp., v.17, p.1013-1026, 1995.

EGAMI, M.I.; SASSO, W.S. Cytochemical observations of blood cells of Bothrops jararaca (Reptilia, Squamata). Rev. Bras. Biol., v.48, p.155-159, 1988.

GREGO, K.F.; ALVES, J.A.S.; RAMEH, A.L.C. et al. Referências hematológicas para a jararacas de rabo branco (Bothrops leucurus) recém capturadas da natureza. Arq. Bras. Med. Vet. Zootec., v.58, p.1240-1243, 2006. 
HAWKEY, C.M.; DENNETT, T.B. Normal and abnormal red cells, granulocytes, lymphocytes, and azurophilis. In Hawkey C.M., Dennett T.B. (Eds.). Color atlas of comparative veterinary hemotology. Ames: Iowa State University Press, 1989.

JAIN, N.C. Cytochemistry of normal and leukemic leukocytes. In: Schalm's veterinary hematology. Philadelphia: Lea \& Febiger. 1986. p.909-939.

KINDLOVITS, L.M. Caracterização ultraestrutural das células sanguíneas de cascavéis (Crotalus linnaeus, 1758) pertencentes ao serpentário científico do Instituto Vital Brazil S.A. Niterói/RJ. 2012. $\quad$ 86f. Dissertação (Mestrado em Medicina veterinária) - Faculdade de Veterinária, Universidade Federal Fluminense, Niterói, RJ.

MADER, D.R. Reptile medicine and surgery. Philadelphia: W.B. Saunders, 2006. 512p.

MATEO, M.R.; ROBERTS E.D.; ENRIGHT F.M. Morphologic, cytochemical and functional studies of peripheral blood cells of young healthy American alligators (Alligator mississippiensis). Am. J. Vet. Res., v.45, p.1046-1053. 1984.

McDONALD, H.S. Methods for the physiological study of reptiles. In.: GANS, C. (Ed.). Biology of reptilia: physiology A. New York: Academic Press. 1976. v.5. p.19-126.

MONTALI, R.K. Comparative pathology of inflammation in higher vertebrates (reptiles, birds, and mammals). J. Comp. Path., v.99, p.1$26,1988$.

RODRIGUES, L.M. Avaliação morfológica $e$ citoquímica das células sanguíneas de serpentes dos gêneros Bothrops Wagler, 1824 e Crotalus Linnaeus, 1758. 2000. 82f. Dissertação (Mestrado em Medicina Veterinária) Faculdade de Veterinária, Universidade Federal Fluminense, Niterói, RJ.
ROVIRA, A.R.I. Schalm's veterinary hematology. Iowa: Lippincott Wiley-blackwell, 2010. p.10041012.

SAINT GIRONS, M.C. Morphology of the circulating blood cells. In: GANS, C. (Ed.). Biology of reptilia: morphology C. New York: Academic Press, 1970. v.3, p.73-92.

SALAKIJ, C.; SALAKIJ, J.; APIBAL, S.; et al. Hematology, morphology, cytochemical staining, and ultrastuctural characteristics of blood cells in king cobras (Ophiophagus hannah). Vet. Clin. Pathol., v.31, p.116-126, 2002.

SANTOS, K.R. Implicações do parasitismo por nematódeos do gênero rhabdias (Nematoda, Rhabdiasidae) em Crotalus durissus terrificus (Serpentes, Viperidae): alterações pulmonares, microbiológicas e hematológicas. 2005. 51f. Dissertação (Mestrado em Medicina Veterinária) - Faculdade de Medicina Veterinária e Zootecnia, Universidade Estadual Paulista Júlio de Mesquita Filho, Botucatu, SP.

SANTOS, L.C.; CUBAS, P.H. Coleta e conservação de amostras biológicas. In: CUBAS, Z.S.; SILVA， J.C.R.; CATÃO-DIAS， J.L. Tratado de animais selvagens. São Paulo: Roca, 2007, p.930-938.

SILVA, W.B.; MACHADO, C.; GOLDBERG, D.W. et al. Avaliação da resposta inflamatória hematológica em cascavéis (Crotalus durissus Linnaeus, 1758) inoculadas com BCG. Pesqui. Vet. Bras., v.29, p.985-992, 2009.

SILVA, W.B.; SOARES, R.M.; MACHADO, C. et al. .Bioquímica plasmática de cascavéis (Caudisona durissa LINNAEUS, 1758) em cativeiro. Ciênc. Rural, v.40, p.2510-2514, 2010.

TROIANO, J.C.; VIDAL, J.C.; GOULD, J.; GOULD, E. Haematological reference intervals of the South American Rattlesnake (Crotalus durissus terrificus, Laurent, 1768) in Captivity. Comp. Haematol. Internat., v.1, p.109-112, 1997. 